\title{
Modified vs. standard D2 lymphadenectomy in distal subtotal gastrectomy for locally advanced gastric cancer patients under 70 years of age
}

\author{
CHUN-DONG ZHANG ${ }^{1 *}$, LIANG ZONG $^{2-4 *}$, FEI-LONG NING $^{1}$, XIAN-TAO ZENG $^{5}$ and DONG-QIU DAI ${ }^{1,6,7}$ \\ ${ }^{1}$ Department of Gastrointestinal Surgery, The Fourth Affiliated Hospital of China Medical University, \\ Shenyang, Liaoning 110032; ${ }^{2}$ Key Laboratory of Carcinogenesis and Translational Research (Ministry of Education), \\ Department of Gastrointestinal Surgery, Peking University Cancer Hospital and Institute, Beijing 100142, P.R. China; \\ ${ }^{3}$ Department of Gastrointestinal Surgery, Graduate School of Medicine, University of Tokyo, Tokyo 113-8654, Japan; \\ ${ }^{4}$ Department of Gastrointestinal Surgery, Clinical Medical College of Yangzhou University, Northern Jiangsu People's \\ Hospital, Yangzhou, Jiangsu 225001; ${ }^{5}$ Center for Evidence-Based and Translational Medicine, Zhongnan Hospital of Wuhan \\ University, Wuhan, Hubei 430072; ${ }^{6}$ Cancer Research Institute, China Medical University, Shenyang, Liaoning 110122; \\ ${ }^{7}$ Cancer Center, The Fourth Affiliated Hospital of China Medical University, Shenyang, Liaoning 110032, P.R. China
}

Received July 1, 2017; Accepted October 20, 2017

DOI: $10.3892 / \mathrm{ol} .2017 .7277$

\begin{abstract}
The present study was conducted to investigate the prognosis and survival of patients with locally advanced gastric cancer who underwent distal subtotal gastrectomy with modified D2 (D1+) and D2 lymphadenectomy, under 70 years of age. The five-year overall survival rates of 390 patients were compared between those receiving D1+ and D2 lymphadenectomy. Univariate and multivariate analyses were used to identify factors that correlated with prognosis and lymph node metastasis. Tumor size $(\mathrm{P}=0.039)$, $\mathrm{pT}$ stage $(\mathrm{P}=0.011)$, $\mathrm{pN}$ stage $(\mathrm{P}<0.001)$, and lymphadenectomy $(\mathrm{P}=0.004)$ were identified as independent prognostic factors. Furthermore, tumor
\end{abstract}

Correspondence to: Professor Dong-Qiu Dai, Department of Gastrointestinal Surgery, The Fourth Affiliated Hospital of China Medical University, 4 Chongshan East Road, Shenyang, Liaoning 110032, P.R. China

E-mail: daidq63@163.com; cmudaidq@126.com

*Contributed equally

Abbreviations: UICC, International Union Against Cancer; AJCC, American Joint Committee on Cancer; JGCA, Japanese Gastric Cancer Association; NCCN, national comprehensive cancer network; R0, negative resection margins; OS, overall survival; RR, relative risk; SD, standard deviation; 95\% CI, 95\% confidence interval; LN, lymph node; LVI, lymphovascular invasion; D1+, modified D2 lymphadenectomy; D2, standard D2 lymphadenectomy; CEA, carcino-embryonic antigen; CT, computer tomography

Key words: prognostic significance, gastric cancer, TNM staging system, lymph nodes, lymphadenectomy, standard D2, modified D2 (D1+) size $(\mathrm{P}=0.022)$, pT stage $(\mathrm{P}=0.012)$, and lymphadenectomy $(\mathrm{P}=0.028)$ were proven as independent factors predicting lymph node metastasis. In conclusion, cancers of larger size, higher pT stage, and with D1+ lymphadenectomy had a higher risk of lymph node metastasis. Standard D2 lymphadenectomy removes sufficient lymph nodes to improve staging accuracy and survival. Therefore, D2 lymphanectomy is recommended in distal subtotal gastrectomy for locally advanced gastric cancer, especially for cancers of larger size and higher pT stage.

\section{Introduction}

Gastric cancer is common and remains a major public health problem around the world (1-3). The incidence of gastric cancer has declined recently; however, it remains the fifth most frequently diagnosed cancer and the second leading cause of cancer-related death globally (4). Unfortunately, gastric cancer is often diagnosed at an advanced stage in China, and this is associated with poor survival. Radical surgery remains the primary potentially curative therapy for patients with resectable gastric cancer.

It is known that the number of metastatic lymph nodes (LNs) is one of the most important prognostic factors for patients with gastric cancer. Both the International Union Against Cancer (UICC)/American Joint Committee on Cancer (AJCC) and the Japanese Gastric Cancer Association (JGCA) recommend a goal of $\geq 15$ LNs examined for optimal staging $(3,5)$. A more extensive LN dissection helps to improve staging accuracy and survival outcomes of patients with advanced gastric cancer (6-8). However, the beneficial survival outcome of more extensive LN dissection may only be associated with stage migration or staging accuracy; its direct contribution to improved survival remains unclear $(9,10)$. Moreover, more extensive LN dissection may increase operation-related morbidity and mortality. 
The efficacy of various types of $\mathrm{LN}$ dissection remains controversial (11-14). In the West, D1 or a modified D2 lymphadenectomy (i.e., D1+) for gastrectomy has been identified as the gold standard treatment for localized resectable gastric cancer, and standard D2 lymphadenectomy is considered only a recommended but not a required procedure $(3,6,13,15,16)$. In eastern Asia, especially in Japan and China, standard D2 lymphadenectomy has been the standard surgical therapy for curable gastric cancer. However, D2 lymphadenectomy requires a significant degree of surgical expertise and knowledge. In addition, D1+ lymphadenectomy helps to retrieve more LNs for optimal staging than D1 lymphadenectomy, and with lower postoperative mortality and morbidity than D2 lymphadenectomy. Thus, the efficacy of D1+ lymphadenectomy during gastrectomy, in comparison with D2 lymphadenectomy, in eastern Asia remains unclear. The incidence of gastric cancer in China is the highest in the world (17).

The average lifespans of men and women in China are 74 and 77 years, respectively. Therefore, the long-term effect of curative gastrectomy for gastric cancer may not be evaluable in such elderly patients (18). In the light of these considerations, we conducted this study to investigate the prognosis and survival outcomes, comparing D1+ and standard D2 lymphadenectomy in distal subtotal gastrectomy for locally advanced patients under 70 years of age in China.

\section{Patients and methods}

Patients. Between May 1987 and February 2014, patients with advanced gastric cancer, who underwent subtotal gastrectomy in the Department of Gastrointestinal Surgery of the Fourth Affiliated Hospital and Cancer Research Institute of China Medical University, were entered into a retrospectively maintained database. In total, 397 patients with locally advanced gastric cancer underwent distal subtotal gastrectomy with D1+ or D2 lymphadenectomy. All patients achieved a potentially curative resection for histologically proven gastric adenocarcinoma. This study was approved by the Ethics Committee of the Fourth Affiliated Hospital, China Medical University. All patient records and information were anonymized and de-identified prior to analysis. Research was conducted in accordance with the principals of the 1964 Declaration of Helsinki and its later amendments.

Included and excluded standards. The inclusion criteria were as follows: Patients under 70 years of age; histologically proven adenocarcinoma; cancers in pT2-4aN0-3M0 stage; negative resection margins (R0); potentially curable, and a curative operation was performed; complete medical records were available; with D1+ or D2 lymphadenectomy. The exclusion criteria were as follows: Preoperative adjuvant therapy; previous or concomitant other cancer; emergency surgery; and patients lost to follow-up.

Follow-up. The follow-up of the entire study population was complete until death or the cutoff date (October 2014). All the patients gave a history and underwent physical examination, and their carcino-embryonic antigen (CEA) levels were assessed every 3 to 6 months for the first postoperative year, and every 6 to 12 months thereafter. Seven patients were lost to follow-up and therefore were excluded. The rate of follow-up was $98.2 \%$. Therefore, a total of 390 patients with locally advanced gastric cancer were included in this study.

Clinicopathologic characteristics. The clinicopathologic features that were investigated for prognostic significance included sex, age, previous history, family history of carcinoma, tumor size, blood loss, macroscopic type, histologic grade, lymphatic vessel invasion (LVI), number of LNs retrieved, depth of invasion (pT stage), number of regional $\mathrm{LN}$ metastases ( $\mathrm{pN}$ stage), reconstruction type, inadequate or adequate LNs retrieved, LN metastasis, locoregional recurrence, distant recurrence, and chemotherapy. Among the 390 patients included, 114 (29.2\%) patients underwent D1+ lymphadenectomy, with an average of $7.94 \pm 6.86 \mathrm{LNs}$ retrieved and 2.85 $\pm 4.15 \mathrm{LN}$ metastases; 276 (70.8\%) patients underwent D2 lymphadenectomy, with an average of $17.58 \pm 9.24$ LNs retrieved and 4.43 $\pm 4.91 \mathrm{LN}$ metastases (Table I).

D1+ and D2 lymphadenectomy. According to the Japanese Gastric Cancer Treatment Guidelines of the Japanese Gastric Cancer Association (JGCA), D1 lymphadenectomy for distal gastrectomy includes stations Nos. 1, 3, 4sb, 4d, 5, 6, 7; D1+ lymphadenectomy includes D1 and stations Nos. 8a, 9; D2 lymphadenectomy includes D1 and stations Nos. 8a, 9, 11p, $12 \mathrm{a}(5)$.

Pathology. Two pathologists independently examined the histologic sections, and disagreements were resolved by discussion to determine the final diagnosis. The carcinoma lesions together with the surrounding gastric wall were fixed in formalin and cut into multiple $5 \mathrm{~mm}$ slices, which were parallel to the lesser curvature. As many LNs as possible were retrieved for adequate staging. According to the current guidelines for gastric cancer, examining at least 15 LNs is strongly recommended for adequate staging $(6,13)$. The 8 th Edition of the AJCC TNM staging classification for carcinoma of the stomach was applied to re-stage the cancers of all patients in this study. The pathology report generally included tumor size, pT, pN, status of margin, LVI, status of mucosa, status of LNs, number of LNs retrieved, macroscopic type, and histologic grade.

Statistical analysis. Five-year overall survival (OS) rates were calculated using Kaplan-Meier survival analysis. The number at risk was also shown in all Kaplan-Meier curves. Two-sided $\chi^{2}$ tests or two-tailed t-tests were performed for comparison of clinicopathologic features between patients who underwent D1+ and D2 lymphadenectomy. The log-rank (Mantel-Cox) test was conducted in the univariate analysis to identify independently significant prognostic factors and prognostic factors correlated with LN metastasis. Multivariate analysis was applied to identify significant factors correlated with prognosis, including lymphadenectomy and all significant factors identified by univariate analysis. Univariate analysis was firstly applied to find the potential prognostic factors. Then multivariate analysis was applied to identify significant factors correlated with prognosis, including all significant factors identified by the univariate analysis and the factor lymphadenectomy. Moreover, scatter-plots and population pyramid 
Table I. Clinicopathologic features of patients who underwent D1+ and D2 lymphadenectomy $(n=390)$.

\begin{tabular}{|c|c|c|c|}
\hline Variables & D1+ lymphadenectomy $n=114(\%)$ & D2 lymphadenectomy $n=276(\%)$ & P-value \\
\hline Sex & & & 0.276 \\
\hline Female & $30(26.3)$ & $88(31.9)$ & \\
\hline Male & $84(73.7)$ & $188(68.1)$ & \\
\hline Age (years) & $59.24 \pm 11.17$ & $58.59 \pm 11.88$ & 0.621 \\
\hline Previous history & & & 0.799 \\
\hline Gastritis and (or) ulcer & $32(28.1)$ & $74(26.8)$ & \\
\hline None & $82(71.9)$ & $202(73.2)$ & \\
\hline Family history of carcinoma & & & 0.058 \\
\hline Yes & $26(22.8)$ & $41(14.9)$ & \\
\hline No & $88(77.2)$ & $235(85.1)$ & \\
\hline Tumor size $(\mathrm{cm})$ & $5.89 \pm 3.78$ & $4.87 \pm 2.17$ & $0.001^{\mathrm{a}}$ \\
\hline Blood loss & & & $0.048^{\mathrm{a}}$ \\
\hline$<200 \mathrm{ml}$ & $57(50.0)$ & $108(39.1)$ & \\
\hline$\geq 200 \mathrm{ml}$ & $57(50.0)$ & $168(60.9)$ & \\
\hline Macroscopic type & & & $0.014^{\mathrm{a}}$ \\
\hline Borrmann 1 & $6(5.3)$ & $5(1.8)$ & \\
\hline Borrmann 2 & $35(30.7)$ & $56(20.3)$ & \\
\hline Borrmann 3 & $65(57.0)$ & $201(72.8)$ & \\
\hline Borrmann 4 & $8(7.0)$ & $14(5.1)$ & \\
\hline Histologic grade & & & $<0.001^{\mathrm{a}}$ \\
\hline Well differentiated & $32(28.1)$ & $41(14.9)$ & \\
\hline Moderately differentiated & $23(20.2)$ & $50(18.1)$ & \\
\hline Poorly differentiated & $50(43.8)$ & $178(64.5)$ & \\
\hline Undifferentiated & $9(7.9)$ & $7(2.5)$ & \\
\hline Lymphatic vessels invasion & & & 0.881 \\
\hline Negative & $90(78.9)$ & $216(78.3)$ & \\
\hline Positive & $24(21.1)$ & $60(21.7)$ & \\
\hline Number of LNs retrieved & $7.94 \pm 6.86$ & $17.58 \pm 9.24$ & $<0.001^{\mathrm{a}}$ \\
\hline pT stage & & & 0.269 \\
\hline pT2 & $15(13.2)$ & 55 (19.9) & \\
\hline pT3 & $59(51.7)$ & $136(49.3)$ & \\
\hline pT4a & $40(35.1)$ & $85(30.8)$ & \\
\hline $\mathrm{pN}$ stage & & & $<0.001^{\mathrm{a}}$ \\
\hline pNO & $44(38.6)$ & $53(19.2)$ & \\
\hline $\mathrm{pN} 1$ & $36(31.6)$ & $75(27.2)$ & \\
\hline $\mathrm{pN} 2$ & $17(14.9)$ & $85(30.8)$ & \\
\hline $\mathrm{pN} 3$ & $17(14.9)$ & $63(22.8)$ & \\
\hline Number of metastatic LNs & $2.85 \pm 4.15$ & $4.43 \pm 4.91$ & $0.003^{\mathrm{a}}$ \\
\hline Reconstruction type & & & $<0.001^{\mathrm{a}}$ \\
\hline Billroth I & $64(56.1)$ & $225(81.5)$ & \\
\hline Billroth II & $50(43.9)$ & $51(18.5)$ & \\
\hline Number of LNs retrieved & & & $<0.001^{\mathrm{a}}$ \\
\hline Inadequate $(\mathrm{n}<15)$ & $88(77.2)$ & $99(35.9)$ & \\
\hline Adequate $(n \geq 15)$ & $26(22.8)$ & $177(64.1)$ & \\
\hline LN metastasis & & & $<0.001^{\mathrm{a}}$ \\
\hline No & $44(38.6)$ & $53(19.2)$ & \\
\hline Yes & $70(61.4)$ & $223(80.8)$ & \\
\hline Locoregional recurrence & & & 0.072 \\
\hline Absent & $87(76.3)$ & $232(84.1)$ & \\
\hline Present & $27(23.7)$ & $44(15.9)$ & \\
\hline
\end{tabular}


Table I. Continued.

\begin{tabular}{|c|c|c|c|}
\hline Variables & D1+ lymphadenectomy $n=114(\%)$ & D2 lymphadenectomy $n=276(\%)$ & P-value \\
\hline Distant recurrence & & & 0.208 \\
\hline Absent & $82(71.9)$ & $215(77.9)$ & \\
\hline Present & $32(28.1)$ & $61(22.1)$ & \\
\hline Chemotherapy & & & 0.117 \\
\hline No & $78(68.4)$ & $210(76.1)$ & \\
\hline Yes & $36(31.6)$ & $66(23.9)$ & \\
\hline
\end{tabular}

${ }^{\text {a }}$ Two tailed t-tests of mean \pm standard deviation; $n$, number of patients; LNs, lymph nodes.
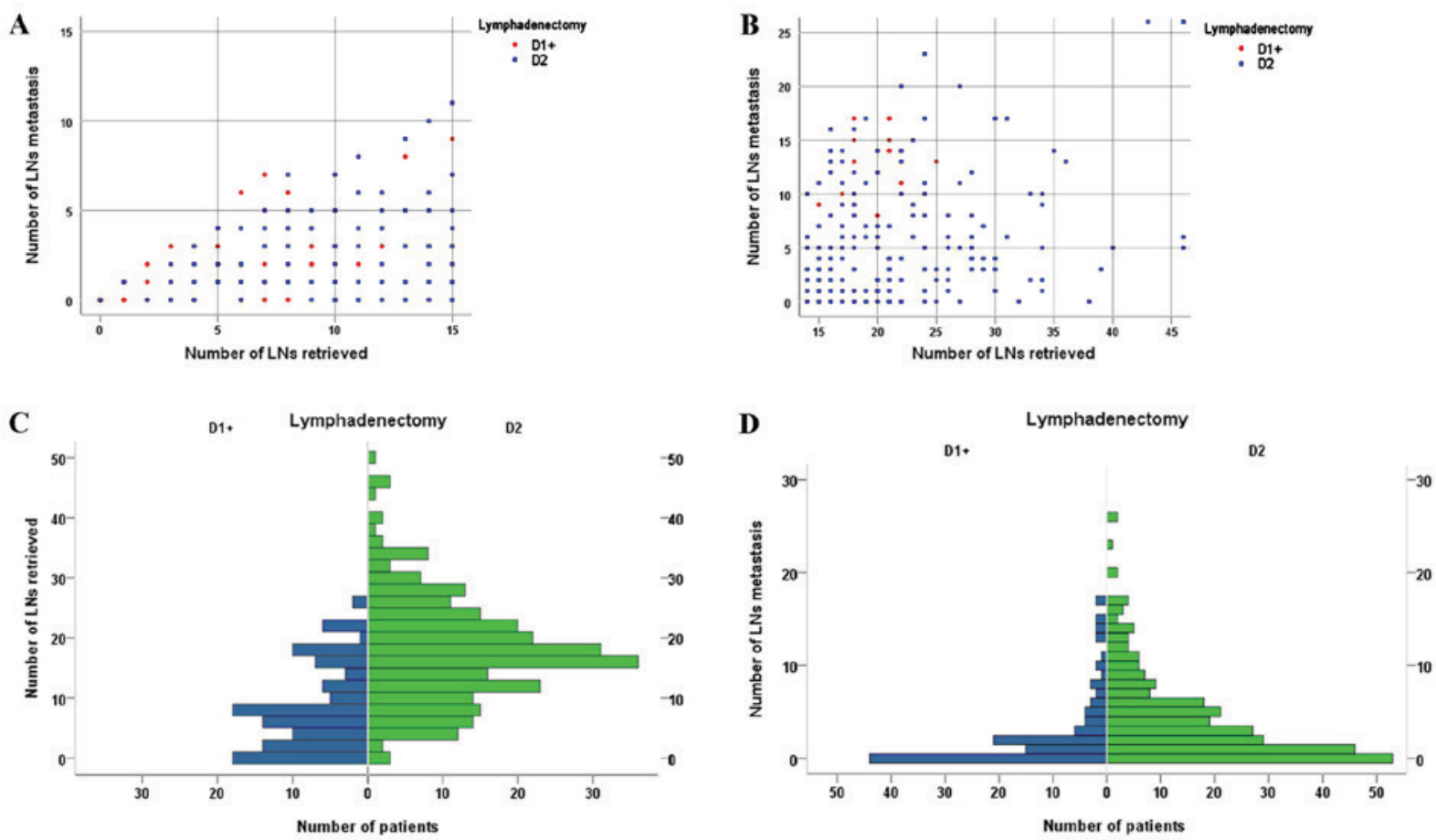

Figure 1. (A) The distribution of the number of metastatic LNs according to the number of LNs retrieved for patients with $\leq 15$ LNs retrieved, comparing D1+ with D2 lymphadenectomy. (B) The distribution of the number of metastatic LNs according to the number of LNs retrieved for patients with $>15$ LNs retrieved, comparing D1+ with D2 lymphadenectomy. (C) The number of patients according to the number of LNs retrieved, comparing D1+ with D2 lymphadenectomy. (D) The number of patients according to the number of metastatic LNs, comparing D1+ with D2 lymphadenectomy.

figures were used to compare the distribution of metastatic LNs and retrieved LNs between patients who underwent D1+ and D2 lymphadenectomy. A P-value of less than 0.05 was defined as statistically significant. IBM SPSS v.22.0 statistical software was used for all statistical analyses (SPSS Inc., Chicago, IL, USA).

\section{Results}

In total, 390 patients with locally advanced gastric cancer who underwent distal subtotal gastrectomy were assessed for eligibility in this study. The age of the entire population ranged from 30 to 70 years. Of these patients, 114 patients underwent D1+ lymphadenectomy and 276 patients underwent D2 lymphadenectomy. Among the patients who underwent D1+ lymphadenectomy, 30 (26.3\%) were female and $84(73.7 \%)$ were male; among those who underwent D2 lymphadenectomy, 88 (31.9\%) were female and $188(68.1 \%)$ were male.

Clinicopathologic features. The two groups (D1+ vs. D2 lymphadenectomy) were well balanced in sex $(\mathrm{P}=0.276)$, age $(\mathrm{P}=0.621)$, previous history $(\mathrm{P}=0.799)$, family history of carcinoma $(\mathrm{P}=0.058)$, and chemotherapy $(\mathrm{P}=0.117)$ (Table I). The median number of LNs retrieved was significantly higher with D2 than D1+ lymphadenectomy (17.58 \pm 9.24 vs. $7.94 \pm 6.86$; $\mathrm{P}<0.001)$. A significant difference could be found in the number of LN metastases when comparing D2 and D1+ lymphadenectomy $(4.43 \pm 4.91$ vs. $2.85 \pm 4.15, \mathrm{P}=0.003)$. Similarly, significant differences were found with regard to tumor size $(\mathrm{P}=0.001)$, blood loss $(\mathrm{P}=0.048)$, macroscopic type $(\mathrm{P}=0.014)$, histologic grade $(\mathrm{P}<0.001)$, pN stage $(\mathrm{P}<0.001)$, reconstruction type $(\mathrm{P}<0.001)$, and LN metastasis $(\mathrm{P}<0.001)$ when comparing D2 and D1+ lymphadenectomy. No significant difference could 
Table II. Univariate and multivariable analysis of prognostic factors for the entire study population $(n=390)$.

\begin{tabular}{|c|c|c|c|c|c|c|}
\hline \multirow[b]{2}{*}{ Variables } & \multicolumn{3}{|c|}{ Univariate analysis } & \multicolumn{3}{|c|}{ Multivariate analysis } \\
\hline & $n(\%)$ & 5-YSR (\%) & $\mathrm{P}$-value & RR & $95 \% \mathrm{CI}$ & P-value \\
\hline Sex & & & 0.706 & & & \\
\hline Female & $118(30.3)$ & 45.8 & & & & \\
\hline Male & $272(69.7)$ & 40.6 & & & & \\
\hline Age (years) & & & 0.308 & & & \\
\hline$<65$ & $245(62.8)$ & 40.9 & & & & \\
\hline$\geq 65$ & $145(37.2)$ & 50.1 & & & & \\
\hline Tumor size (cm) & & & $0.003^{\mathrm{a}}$ & 1.429 & $1.017-2.007$ & $0.039^{\mathrm{a}}$ \\
\hline$<4$ & $87(22.3)$ & 52.9 & & & & \\
\hline$\geq 4$ & $303(77.7)$ & 41.7 & & & & \\
\hline Macroscopic type & & & 0.279 & & & \\
\hline Borrmann 1 & $11(2.8)$ & 39.0 & & & & \\
\hline Borrmann 2 & $91(23.3)$ & 52.7 & & & & \\
\hline Borrmann 3 & $266(68.2)$ & 41.7 & & & & \\
\hline Borrmann 4 & $22(5.7)$ & 37.3 & & & & \\
\hline Histological grade & & & 0.400 & & & \\
\hline Well differentiated & $73(18.7)$ & 55.9 & & & & \\
\hline Moderately differentiated & $73(18.7)$ & 34.3 & & & & \\
\hline Poorly differentiated & $228(58.5)$ & 44.8 & & & & \\
\hline Undifferentiated & $16(4.1)$ & 34.7 & & & & \\
\hline Lymphatic vessels invasion & & & 0.068 & & & \\
\hline Negative & $306(78.5)$ & 46.0 & & & & \\
\hline Positive & $84(21.5)$ & 37.8 & & & & \\
\hline pT stage & & & $0.005^{\mathrm{a}}$ & 1.279 & $1.059-1.545$ & $0.011^{\mathrm{a}}$ \\
\hline pT2 & $70(17.9)$ & 60.2 & & & & \\
\hline pT3 & $195(50.0)$ & 47.0 & & & & \\
\hline pT4a & $125(32.1)$ & 31.6 & & & & \\
\hline pN stage & & & $0.008^{\mathrm{a}}$ & 1.302 & $1.139-1.487$ & $<0.001^{\mathrm{a}}$ \\
\hline pNO & $97(24.9)$ & 50.2 & & & & \\
\hline $\mathrm{pN} 1$ & $111(28.5)$ & 49.5 & & & & \\
\hline $\mathrm{pN} 2$ & $102(26.1)$ & 46.1 & & & & \\
\hline $\mathrm{pN} 3$ & $80(20.5)$ & 25.0 & & & & \\
\hline Reconstruction type & & & $0.012^{\mathrm{a}}$ & & & \\
\hline Billroth I & $289(74.1)$ & 47.1 & & & & \\
\hline Billroth II & $101(25.9)$ & 36.2 & & & & \\
\hline Lymphadenectomy & & & $0.018^{\mathrm{a}}$ & 0.653 & $0.490-0.870$ & $0.004^{\mathrm{a}}$ \\
\hline D1+ & $114(29.2)$ & 35.7 & & & & \\
\hline D2 & $276(70.8)$ & 48.2 & & & & \\
\hline Number of LNs retrieved & & & 0.057 & & & \\
\hline Inadequate $(\mathrm{n}<15)$ & 187 (47.9) & 40.8 & & & & \\
\hline Adequate $(n \geq 15)$ & $203(52.1)$ & 48.9 & & & & \\
\hline LN metastasis & & & 0.170 & & & \\
\hline No & 97 (24.9) & 50.2 & & & & \\
\hline Yes & $293(75.1)$ & 42.1 & & & & \\
\hline Locoregional recurrence & & & 0.274 & & & \\
\hline Absent & $319(81.8)$ & 45.1 & & & & \\
\hline Present & $71(18.2)$ & 38.4 & & & & \\
\hline Distant recurrence & & & 0.238 & & & \\
\hline Absent & $297(76.2)$ & 45.3 & & & & \\
\hline
\end{tabular}


Table II. Continued.

\begin{tabular}{|c|c|c|c|c|c|c|}
\hline \multirow[b]{2}{*}{ Variables } & \multicolumn{3}{|c|}{ Univariate analysis } & \multicolumn{3}{|c|}{ Multivariate analysis } \\
\hline & $n(\%)$ & 5 -YSR $(\%)$ & P-value & RR & $95 \% \mathrm{CI}$ & P-value \\
\hline Present & $93(23.8)$ & 40.8 & & & & \\
\hline Chemotherapy & & & 0.057 & & & \\
\hline No & $288(73.8)$ & 50.3 & & & & \\
\hline Yes & $102(26.2)$ & 36.1 & & & & \\
\hline
\end{tabular}

${ }^{\text {a }} n$, number of patients; LNs, lymph nodes; RR, relative risk; 95\% CI, 95\% confidence interval; 5-YSR, five-year overall survival rate (\%).

be found in LVI $(\mathrm{P}=0.881)$, pT stage $(\mathrm{P}=0.269)$, locoregional recurrence $(\mathrm{P}=0.072)$, and distant recurrence $(\mathrm{P}=0.208)$ when comparing D2 and D1+ lymphadenectomy (Table I).

Fig. 1 shows the distribution of the number of LN metastases according to the number of LNs retrieved for patients with $\leq 15$ LNs retrieved and $>15$ LNs retrieved, comparing D1+ with D2 lymphadenectomy. Fig. 1 also shows the number of patients distributed according to the number of LNs retrieved and the number of LN metastases, comparing D1+ with D2 lymphadenectomy.

Outcomes. As far as we are concerned, lymphadenectomy is very important for patients with gastric cancer surgery, which refers to the removal of regional LNs. And lymphadenectomy may be classified as D0, D1, D1+, or D2 depending on the extent of LNs removed at the time of gastrectomy. More extensive lymph node dissection helps to better accurate staging. Patients with accurate staging may receive ideal postoperative treatments, which may contribute to survival benefit. Therefore, identifying the best lymphadenectomy type for every patient will be of great importance.

To identify which factors were correlated with prognosis and were independent prognostic factors for the entire study population. We firstly conducted univariate analysis to find the potential prognostic factors and then multivariate analysis was applied to identify significant factors correlated with prognosis, including all significant factors identified by the univariate analysis and the factor lymphadenectomy. Firstly, univariate analysis identified tumor size $(\mathrm{P}=0.003)$, pT stage $(\mathrm{P}=0.005), \mathrm{pN}$ stage $(\mathrm{P}=0.008)$, reconstruction type $(\mathrm{P}=0.012)$, and lymphadenectomy $(\mathrm{P}=0.018)$ as potential factors correlated with prognosis for the entire study population (Table II, Fig. 2). Secondly, multivariate analysis demonstrated that tumor size (RR 1.429, 95\% CI 1.017-2.007, $\mathrm{P}=0.039)$, pT stage (RR 1.279, 95\% CI 1.059-1.545, $\mathrm{P}=0.011), \mathrm{pN}$ stage (RR $1.302,95 \% \mathrm{CI}$ $1.139-1.487, \mathrm{P}<0.001)$ and lymphadenectomy (RR 0.653, 95\% CI $0.490-0.870, \mathrm{P}=0.004)$ were independent prognostic factors for the entire study population (Table II). Five-year overall survival rates are also shown (Table II).

To identify which factors were correlated with $\mathrm{LN}$ metastasis, we firstly conducted univariate analysis to find the potential factors correlated with LN metastasis and then multivariate analysis was applied to identify significant factors correlated with LN metastasis, including all significant factors identified by the univariate analysis and the factor lymphadenectomy. Firstly, univariate analysis identified tumor size $(\mathrm{P}=0.006)$ and $\mathrm{pT}$ stage $(\mathrm{P}=0.002)$ as potential factors correlated with LN metastasis (Table III). Secondly, multivariate analysis demonstrated that tumor size (RR 1.486, 95\% CI 1.059-2.087, $\mathrm{P}=0.022)$, pT stage (RR 1.247, 95\% CI $1.055-1.540, \mathrm{P}=0.012)$, and lymphadenectomy (D1+ vs. D2, RR $0.740,95 \%$ CI $0.565-0.969, \mathrm{P}=0.028$ ) were independent prognostic factors predicting LN metastasis (Table III). Survival curves comparing tumor size, $\mathrm{pT}$ stage, reconstruction type, and lymphadenectomy are shown in Fig. 3.

Comparisons of prognosis for patients who underwent D1+ and D2 lymphadenectomy are shown in Table IV, as stratified by $\mathrm{pT}$ stage, $\mathrm{pN}$ stage, and the number of LNs retrieved. As shown, D2 lymphadenectomy helped to achieve a higher 5-year OS rate, compared with D1+ lymphadenectomy for the entire sample of patients (35.7\% for D1+, $48.2 \%$ for D2) and for patients in stage pT2 $(51.9 \%$ for D1+, $63.0 \%$ for D2), pT3 (38.3\% for D1+, $51.8 \%$ for D2), pT4a (25.9\% for D1+, $34.3 \%$ for D2), $\mathrm{pN} 0$ (36.6\% for D1+, 63.9\% for D2), $\mathrm{pN} 1$ (42.7\% for $\mathrm{D} 1+, 52.7 \%$ for $\mathrm{D} 2), \mathrm{pN} 2$ (32.7\% for $\mathrm{D} 1+, 49.2 \%$ for $\mathrm{D} 2)$, and pN3 (17.7\% for D1+, $27.7 \%$ for D2), as well as patients with adequate $(34.3 \%$ for $\mathrm{D} 1+, 46.9 \%$ for D2) or inadequate $\mathrm{LN}$ retrieval (44.7\% for D1+, $49.6 \%$ for D2). Importantly, a statistically significant difference in 5-year OS rate could be found in the entire study population $(35.7 \%$ for $\mathrm{D} 1+, 48.2 \%$ for $\mathrm{D} 2$, log-rank test, $\mathrm{P}=0.018$ ), and especially for patients with $\mathrm{pN} 0$ cancer $(36.6 \%$ for $\mathrm{D} 1+, 63.9 \%$ for $\mathrm{D} 2$, log-rank test, $\mathrm{P}=0.021)$.

\section{Discussion}

Radical surgery is still the primary potentially curable treatment for resectable gastric cancer, and R0 resection is recommended as the gold standard. For patients with distal gastric cancer, subtotal gastrectomy is preferred for its similar outcomes and fewer complications, when compared with total gastrectomy (19). Therefore, in this study, only patients with locally advanced gastric cancer who underwent subtotal gastrectomy were included. In addition, the average lifespans of men and women in China are 74 and 77 years, respectively. Therefore, if we include patients older than age of 70 years, the long-term effect of curative gastrectomy for gastric cancer may not be evaluable; thus, we only included patients under age of 70 years in this study.

Recently, D1 or D1+ lymphadenectomy for gastrectomy has been identified as the gold standard treatment for 
$\mathbf{A}$

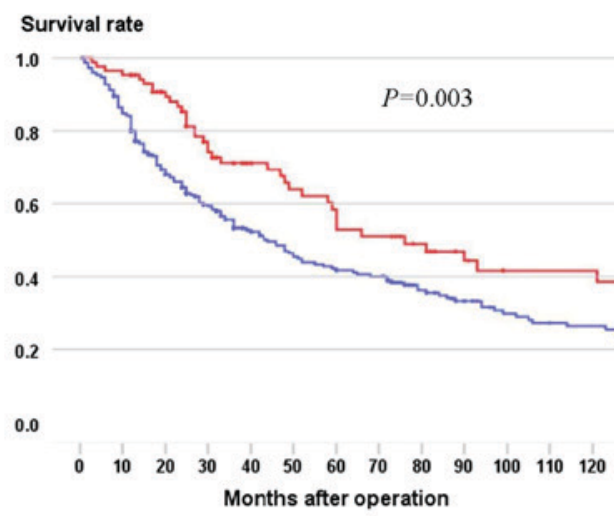

Number at risk

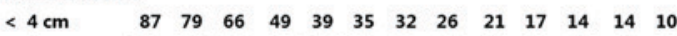

$\begin{array}{lllllllllllllll}2 & 4 \mathrm{~cm} & 300 & 244 & 171 & 126 & 100 & 87 & 78 & 65 & 49 & 41 & 35 & 31 & 22\end{array}$

\section{Survival rate}

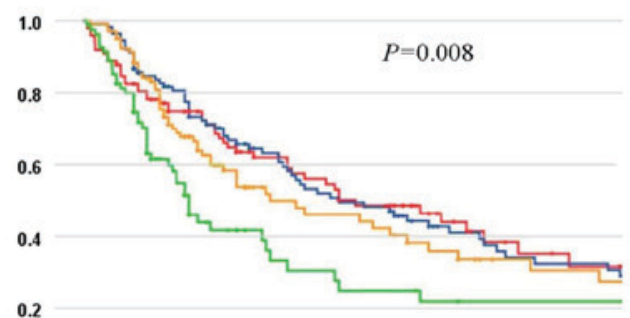

0.0

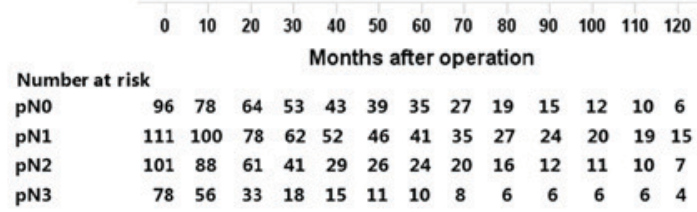

$\mathbf{E}$
Tumor size

$\unlhd<4$

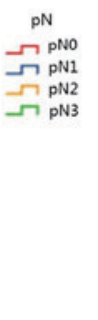

D

B

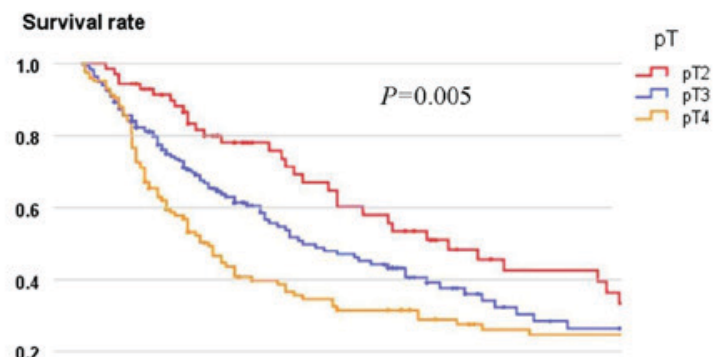

0.0

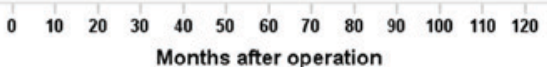

Number at risk

$\begin{array}{lccccccccccccc}\text { Number at risk } & & & & & & & & & \\ \text { pT2 } & 70 & 63 & 55 & 41 & 35 & 32 & 29 & 25 & 20 & 16 & 14 & 14 & 10 \\ \text { pT3 } & 193 & 152 & 112 & 82 & 64 & 54 & 50 & 39 & 27 & 21 & 17 & 14 & 9 \\ \text { pT4a } & 124 & 107 & 69 & 51 & 40 & 36 & 31 & 27 & 22 & 20 & 18 & 17 & 13\end{array}$

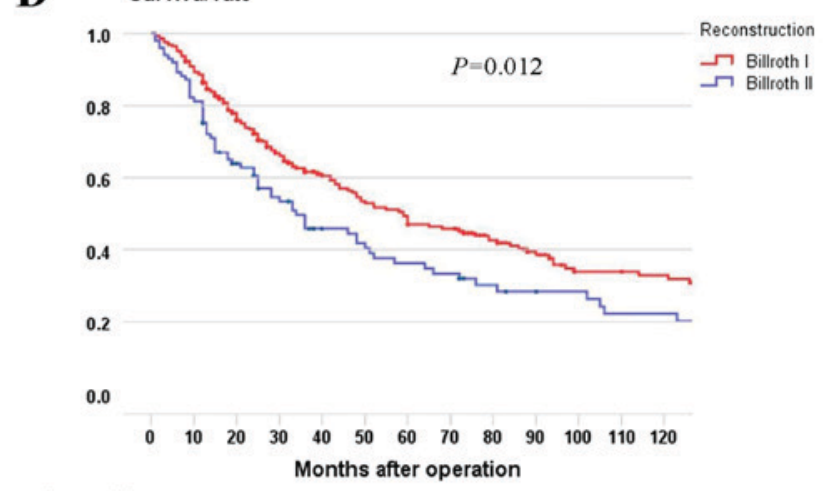

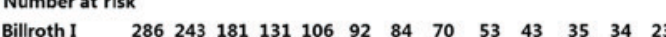

$\begin{array}{lllllllllllllll}\text { Billroth II } & 101 & 80 & 56 & 43 & 33 & 30 & 26 & 21 & 16 & 14 & 14 & 11 & 9\end{array}$

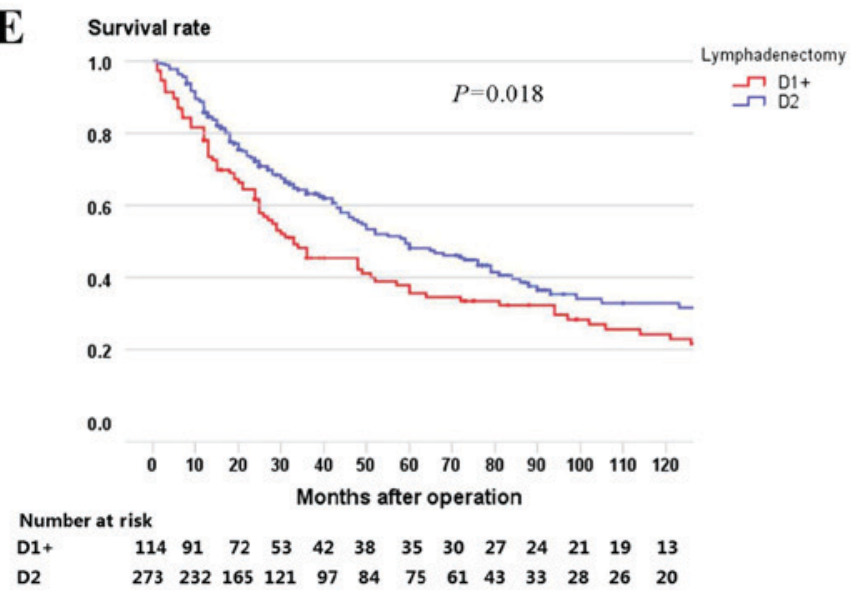

Figure 2. (A) Kaplan-Meier curve for the entire study population according to tumor size ( $\mathrm{P}=0.003)$. (B) Kaplan-Meier curve for the entire study population according to $\mathrm{pT}$ stage $(\mathrm{P}=0.005)$. (C) Kaplan-Meier curve for the entire study population according to $\mathrm{pN}$ stage $(\mathrm{P}=0.008)$. (D) Kaplan-Meier curve for the entire study population according to reconstruction type $(\mathrm{P}=0.012)$. (E) Kaplan-Meier curve for the entire study population according to lymphadenectomy $(\mathrm{P}=0.018)$.

localized resectable gastric cancer in the West; however, D2 lymphadenectomy is considered only a recommended but not a required procedure, which may only contribute to accurate staging $(3,6,13,15,16)$. In addition, its contribution to survival benefit is under debate and may be due to the effect of 'stage migration'. D2 lymphadenectomy has been a standard therapy for curable gastric cancer in eastern Asia; however, it was reported to be associated with significantly higher postoperative mortality and morbidity, when compared with D1 lymphadenectomy (11). As far as we are concerned, D1+ lymphadenectomy helps to retrieve more LNs for optimal staging than D1 lymphadenectomy, and D1+ lymphadenectomy may be associated with lower postoperative mortality and morbidity than D2 lymphadenectomy. Thus, the efficacy 
Table III. Univariate and multivariate analysis of factors predicting LN metastasis $(n=293)$.

\begin{tabular}{|c|c|c|c|c|c|c|}
\hline \multirow[b]{2}{*}{ Variables } & \multicolumn{3}{|c|}{ Univariate analysis } & \multicolumn{3}{|c|}{ Multivariate analysis } \\
\hline & LN metastasis (+) & 5 -YSR (\%) & $\mathrm{P}$-value & $\mathrm{RR}$ & $95 \% \mathrm{CI}$ & P-value \\
\hline Sex & & & 0.475 & & & \\
\hline Female & $93(31.7)$ & 37.5 & & & & \\
\hline Male & $200(68.3)$ & 44.1 & & & & \\
\hline Age (years) & & & 0.527 & & & \\
\hline$<65$ & $190(64.8)$ & 39.1 & & & & \\
\hline$\geq 65$ & $103(35.2)$ & 47.9 & & & & \\
\hline Tumor size $(\mathrm{cm})$ & & & $0.006^{\mathrm{a}}$ & 1.486 & $1.059-2.087$ & $0.022^{\mathrm{a}}$ \\
\hline$<4$ & $65(22.2)$ & 50.7 & & & & \\
\hline$\geq 4$ & $228(77.8)$ & 39.6 & & & & \\
\hline Previous history & & & 0.939 & & & \\
\hline Gastritis and (or) ulcer & $76(25.9)$ & 42.5 & & & & \\
\hline None & $217(74.1)$ & 41.6 & & & & \\
\hline Family history of carcinoma & & & 0.432 & & & \\
\hline No & $246(84.0)$ & 43.3 & & & & \\
\hline Yes & $47(16.0)$ & 35.0 & & & & \\
\hline Macroscopic type & & & 0.197 & & & \\
\hline Borrmann 1 & $8(2.7)$ & 35.0 & & & & \\
\hline Borrmann 2 & $66(22.5)$ & 50.5 & & & & \\
\hline Borrmann 3 & $201(68.6)$ & 39.7 & & & & \\
\hline Borrmann 4 & $18(6.2)$ & 34.4 & & & & \\
\hline Histological grade & & & 0.737 & & & \\
\hline Well differentiated & $50(17.1)$ & 54.1 & & & & \\
\hline Moderately differentiated & $48(16.4)$ & 34.6 & & & & \\
\hline Poorly differentiated & $188(64.1)$ & 41.4 & & & & \\
\hline Undifferentiated & $7(2.4)$ & 28.6 & & & & \\
\hline Lymphatic vessels invasion & & & 0.228 & & & \\
\hline Negative & $221(75.4)$ & 43.1 & & & & \\
\hline Positive & $72(24.6)$ & 39.9 & & & & \\
\hline pT stage & & & $0.002^{\mathrm{a}}$ & 1.274 & $1.055-1.540$ & $0.012^{\mathrm{a}}$ \\
\hline pT2 & $70(23.9)$ & 60.2 & & & & \\
\hline pT3 & $135(46.1)$ & 40.8 & & & & \\
\hline pT4a & $88(30.0)$ & 28.8 & & & & \\
\hline Reconstruction type & & & 0.204 & & & \\
\hline Billroth I & $219(74.7)$ & 43.6 & & & & \\
\hline Billroth II & $74(25.3)$ & 37.6 & & & & \\
\hline Lymphadenectomy & & & 0.085 & 0.740 & $0.565-0.969$ & $0.028^{\mathrm{a}}$ \\
\hline $\mathrm{D} 1+$ & $70(23.9)$ & 34.9 & & & & \\
\hline $\mathrm{D} 2$ & $223(76.1)$ & 44.3 & & & & \\
\hline Number of LNs retrieved & & & 0.351 & & & \\
\hline Inadequate $(\mathrm{n}<15)$ & $122(41.6)$ & 41.7 & & & & \\
\hline Adequate $(\mathrm{n} \geq 15)$ & $171(58.4)$ & 42.4 & & & & \\
\hline
\end{tabular}

${ }^{\mathrm{a}} n$, number of patients; LN, lymph node; RR, relative risk; 95\% CI, 95\% confidence interval; 5-YSR, five-year overall survival rate (\%).

of D1+ lymphadenectomy in eastern Asia is still under debate. D1+ lymphadenectomy in total gastrectomy has been shown to be effective for gastric carcinoma with LN metastasis, but this requires further validation $(20,21)$. This study was conducted to investigate survival outcomes, comparing D1+ and standard D2 lymphadenectomy in distal subtotal 
Table IV. Comparison of prognosis for all patients comparing D1+ and D2 lymphadenectomy $(n=390)$.

\begin{tabular}{|c|c|c|c|c|c|}
\hline \multirow[b]{2}{*}{ Variables } & \multicolumn{2}{|c|}{ D1+ lymphadenectomy } & \multicolumn{2}{|c|}{ D2 lymphadenectomy } & \multirow[b]{2}{*}{ P-value } \\
\hline & $n$ & 5-YSR (\%) & $n$ & 5-YSR (\%) & \\
\hline For the entire population & 114 & 35.7 & 276 & 48.2 & $0.018^{\mathrm{a}}$ \\
\hline \multicolumn{6}{|l|}{ pT stage } \\
\hline $\mathrm{pT} 2$ & $15(13.2)$ & 51.9 & $55(19.9)$ & 63.0 & 0.820 \\
\hline pT3 & $59(51.7)$ & 38.3 & $136(49.3)$ & 51.8 & 0.074 \\
\hline pT4a & $40(35.1)$ & 25.9 & $5(1.8)$ & 34.3 & 0.131 \\
\hline \multicolumn{6}{|l|}{ pN stage } \\
\hline pNO & $44(38.6)$ & 36.6 & $53(19.2)$ & 63.9 & $0.021^{\mathrm{a}}$ \\
\hline $\mathrm{pN} 1$ & $36(31.6)$ & 42.7 & $75(27.2)$ & 52.7 & 0.166 \\
\hline $\mathrm{pN} 2$ & $17(14.9)$ & 32.7 & $85(30.8)$ & 49.2 & 0.642 \\
\hline $\mathrm{pN} 3$ & $17(14.9)$ & 17.7 & $63(22.8)$ & 27.7 & 0.138 \\
\hline \multicolumn{6}{|l|}{ Number of LNs retrieved } \\
\hline Inadequate $(\mathrm{n} \geq 15)$ & $26(22.8)$ & 44.7 & $177(64.1)$ & 49.6 & 0.403 \\
\hline Adequate $(\mathrm{n}<15)$ & $88(77.2)$ & 34.3 & 99 (35.9) & 46.9 & 0.149 \\
\hline
\end{tabular}

a $n$, number of patients; LNs, lymph nodes; RR, relative risk; 95\% CI, 95\% confidence interval; 5-YSR, five-year overall survival rate (\%).
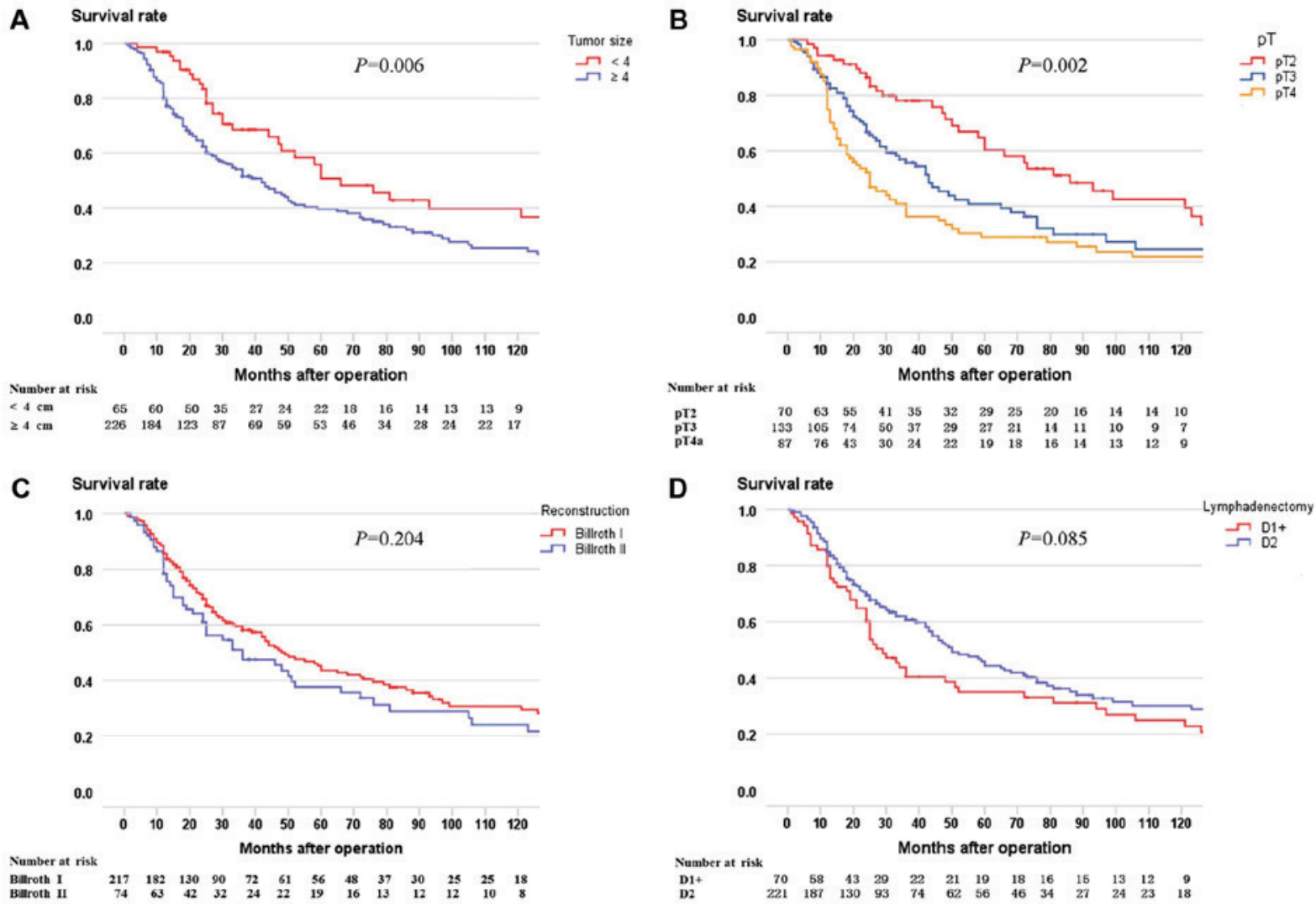

Figure 3. (A) Kaplan-Meier curve for patients with metastatic LNs according to tumor size (P=0.006). (B) Kaplan-Meier curve for patients with metastatic LNs according to pT stage ( $\mathrm{P}=0.002)$. (C) Kaplan-Meier curve for patients with metastatic LNs according to reconstruction type (P=0.204). (D) Kaplan-Meier curve for patients with metastatic LNs according to lymphadenectomy $(\mathrm{P}=0.085)$.

gastrectomy, for patients with locally advanced gastric cancer.

Recurrences were classified as locoregional and distant recurrence. Locoregional recurrence was identified as any cancer recurrence in the gastric bed, anastomotic sites, and regional LNs. Distant recurrence was identified as visceral metastases, peritoneal metastases, and LN metastases beyond the regional LNs. All recurrences were diagnosed clinically 
or radio-graphically, with histopathologic testing or radiography, including computer tomography (CT) scan (head, chest, abdomen, and pelvis) and bone scans; positron emission tomography CT (PET/CT) would be applied if necessary. According to the findings of these examinations, the incidence of recurrence was comparable between patients who underwent D1+ and D2 lymphadenectomy.

To investigate the independent prognostic factors for the entire study population, both univariate and multivariate analyses were performed. We finally identified that tumor size $(\mathrm{P}=0.039)$, pT stage $(\mathrm{P}=0.011)$, pN stage $(\mathrm{P}<0.001)$, and lymphadenectomy $(\mathrm{P}=0.004)$ as independent prognostic factors. Our result is similar to those of many previous studies concerning independent factors for locally advanced gastric cancer.

Both the UICC and JGCA recommend that a sufficient number and level of LNs should be retrieved. A minimum of $15 \mathrm{LNs}$ retrieved is recommended for both the UICC and JGCA staging systems. Insufficient LN retrieval may lead to residual positive LNs. In our study, the median number of LNs retrieved for patients with D1+ lymphadenectomy was significantly less than that of patients with D2 lymphadenectomy $(7.94 \pm 6.86$ for D1+ lymphadenectomy vs. $17.58 \pm 9.24$ for $\mathrm{D} 2$ lymphadenectomy, $\mathrm{P}<0.001)$. The 5-year OS rate of patients with D1+ lymphadenectomy was significantly lower than that of patients with D2 lymphadenectomy (35.7\% for D1+ lymphadenectomy vs. $48.2 \%$ for D2 lymphadenectomy, $\mathrm{P}=0.018$ ). The number of LNs retrieved for patients with D1+ lymphadenectomy is inadequate $(7.94 \pm 6.86)$, which is much fewer than the minimum of $15 \mathrm{LNs}$ as recommended by the UICC and JGCA staging system; therefore, down-staging may occur as a result of residual positive lymph nodes. More extensive lymph node dissection helps to better accurate staging. Thus, patients with accurate staging may receive ideal postoperative treatments, which may contribute to survival benefit. These results indicate that patients would benefit from D2 lymphadenectomy, which helps to retrieve adequate LNs for optimal staging and to improve survival outcomes.

Lymph node metastasis is a poor prognostic factor for gastric cancer and the number of regional LN metastases will influences survival significantly (22). In this current cohort, tumor size $(\mathrm{P}=0.022)$, pT stage $(\mathrm{P}=0.012)$, and lymphadenectomy $(\mathrm{P}=0.028)$ were proved as independent prognostic factors predicting LN metastasis. Accordingly, patients with larger tumor size $(\geq 4 \mathrm{~cm})$, higher pT stage, and who underwent D1+ lymphadenectomy had a higher risk of LN metastasis and shorter survival times. It is not surprising that patients with larger tumor size, higher pT stage, and D1+ lymphadenectomy would have a worse survival outcome. Larger cancers with higher $\mathrm{pT}$ stage are more locally advanced, and may have a higher risk of LN metastasis; therefore, D2 lymphadenectomy is strongly recommended, especially for larger cancers with higher pT stage. As many LNs should be retrieved as possible to avoid residual LNs (as least 15 LNs were recommended), especially for patients with larger tumor size and higher pT stage. However, the results of our study should be interpreted with caution and need to be clarified in further studies.

To evaluate prognosis, 5-year OS rates for patients who underwent D1+ and D2 lymphadenectomy were calculated. According to our study, D2 lymphadenectomy helped to achieve higher 5-year OS rates for the entire study population, patients in pT2-4a and pN0-3 stages, and patients with adequate or inadequate LNs retrieved. Statistically significant differences in 5-year OS rate could be found for the entire study population, and for patients in $\mathrm{pN} 0$ stage. Recent studies have shown that D2 lymphadenectomy is associated with fewer postoperative complications and a trend toward an improved OS rate when performed in high-volume centers with sufficient experience of the operation and postoperative management (23-25). Therefore, we believed that standard D2 lymphadenectomy helps to retrieve adequate LNs and improve staging accuracy and survival outcomes; however, it should be performed by experienced surgeons in high-volume centers.

However, limitations still exist in the present study. First, this retrospective study was based on a follow-up that varied from operation to operation and has changed during the past 27 years. During this large time frame, the effects of surgical progress, surgical techniques, surgical skill and adjuvant therapy may have changed, which may have produced bias. Second, our study lacked the investigation of safety outcomes, such as operation-related morbidity, mortality, and so on, which are also very important and need to be investigated in future studies. Third, it is necessary to note that selection bias may exist because this study was not a randomized controlled trial. Therefore, our study still needs to be validated by future prospective and randomized controlled studies.

In conclusion, cancers of larger size, higher pT stage, and with D1+ lymphadenectomy have higher risk of LN metastasis. This study demonstrated that standard D2 lymphadenectomy helps to retrieve adequate LNs to improve staging accuracy and survival. Therefore, we recommend standard D2 lymphadenectomy in distal subtotal gastrectomy for locally advanced gastric cancer, especially for cancers of larger size and higher pT stage of patients younger than age of 70 years. However, standard D2 lymphadenectomy requires surgeons to have undergone an appropriate learning curve and needs to be performed by experienced surgeons in high-volume centers.

\section{Acknowledgements}

This study was funded by the Natural Science Foundation of Liaoning Province (no. 201602817).

\section{References}

1. Siegel RL, Miller KD and Jemal A: Cancer statistics, 2015. CA Cancer J Clin 65: 5-29, 2015.

2. Goggins WB and Wong GK: Poor survival for US Pacific Islander cancer patients: Evidence from the surveillance, epidemiology, and end results database: 1991 to 2004. J Clin Oncol 25: 5738-5741, 2007.

3. Washington K: 7th edition of the AJCC cancer staging manual: Stomach. Ann Surg Oncol 17: 3077-3079, 2010.

4. Ferlay J, Soerjomataram I, Dikshit R, Eser S, Mathers C, Rebelo M, Parkin DM, Forman D and Bray F: Cancer incidence and mortality worldwide: Sources, methods and major patterns in GLOBOCAN 2012. Int J Cancer 136: E359-E386, 2015.

5. Japanese Gastric Cancer Association: Japanese gastric cancer treatment guidelines 2010 (ver. 3). Gastric Cancer 14: 113-123, 2011.

6. Schwarz RE and Smith DD: Clinical impact of lymphadenectomy extent in resectable gastric cancer of advanced stage. Ann Surg Oncol 14: 317-328, 2007. 
7. Smith DD, Schwarz RR and Schwarz RE: Impact of total lymph node count on staging and survival after gastrectomy for gastric cancer: Data from a large US-population database. J Clin Oncol 23: 7114-7124, 2005 .

8. Eom BW, Joo J, Kim YW, Reim D, Park JY, Yoon HM, Ryu KW, Lee JY and Kook MC: Improved survival after adding dissection of the superior mesenteric vein lymph node $(14 \mathrm{v})$ to standard D2 gastrectomy for advanced distal gastric cancer. Surgery 155 : 408-416, 2014

9. Feinstein AR, Sosin DM and Wells CK: The Will Rogers phenomenon. Stage migration and new diagnostic techniques as a source of misleading statistics for survival in cancer. N Engl J Med 312: 1604-1608, 1985.

10. Seevaratnam R, Bocicariu A, Cardoso R, Yohanathan L, Dixon M, Law C, Helyer L and Coburn NG: How many lymph nodes should be assessed in patients with gastric cancer? A systematic review. Gastric Cancer 15 (Suppl 1): S70-S88, 2012.

11. Hartgrink HH, van de Velde CJ, Putter H, Bonenkamp JJ, Klein Kranenbarg E, Songun I, Welvaart K, van Krieken JH, Meijer S, Plukker JT, et al: Extended lymph node dissection for gastric cancer: Who may benefit? Final results of the randomized Dutch gastric cancer group trial. J Clin Oncol 22: 2069-2277, 2004.

12. Cuschieri A, Weeden S, Fielding J, Bancewicz J, Craven J, Joypaul V, Sydes M and Fayers P: Patient survival after D1 and D2 resections for gastric cancer: Long-term results of the MRC randomized surgical trial. Surgical Co-operative Group. Br J Cancer 79: 1522-1530, 1999.

13. Songun I, Putter H, Kranenbarg EM, Sasako M and van de Velde CJ: Surgical treatment of gastric cancer: 15-year follow-up results of the randomised nationwide Dutch D1D2 trial. Lancet Oncol 11: 439-449, 2010.

14. Sierra A, Regueira FM, Hernández-Lizoáin JL, Pardo F, Martínez-Gonzalez MA and A-Cienfuegos J: Role of the extended lymphadenectomy in gastric cancer surgery: Experience in a single institution. Ann Surg Oncol 10: 219-226, 2003.

15. Degiuli M, Sasako M, Calgaro M, Garino M, Rebecchi F, Mineccia M, Scaglione D, Andreone D, Ponti A and Calvo F; Italian Gastric Cancer Study Group: Morbidity and mortality after D1 and D2 gastrectomy for cancer: Interim analysis of the Italian Gastric Cancer Study Group (IGCSG) randomised surgical trial. Eur J Surg Oncol 30: 303-308, 2004.

16. Degiuli M, Sasako M, Ponti A and Calvo F: Survival results of a multicentre phase II study to evaluate D2 gastrectomy for gastric cancer. Br J Cancer 90: 1727-1732, 2004.
17. Parkin DM, Bray F, Ferlay J and Pisani P: Global cancer statistics, 2002. CA Cancer J Clin 55: 74-108, 2005.

18. Zong L, Abe M, Seto Y and Ji J: Randomized controlled trial of laparoscopic versus open D2 distal gastrectomy for advanced gastric cancer: How should we define the age of included patents? J Clin Oncol: Aug 9, 2016 (Epub ahead of print).

19. Bozzetti F, Marubini E, Bonfanti G, Miceli R, Piano C and Gennari L: Subtotal versus total gastrectomy for gastric cancer: Five-year survival rates in a multicenter randomized Italian trial. Italian Gastrointestinal Tumor Study Group. Ann Surg 230: 170-178, 1999.

20. Galizia G, Lieto E, De Vita F, Castellano P, Ferraraccio F, Zamboli A, Mabilia A, Auricchio A, De Sena G, De Stefano L, et al: Modified versus standard D2 lymphadenectomy in total gastrectomy for nonjunctional gastric carcinoma with lymph node metastasis. Surgery 157: 285-296, 2015.

21. Galizia G, Lieto E, Zamboli A, Auricchio A and Orditura M: Reply 'Modified D2 lymphadenectomy is effective in patients with node-positive gastric cancers undergoing potentially curative total gastrectomy'. Surgery 158: 1447-1448, 2015.

22. Karpeh MS, Leon L, Klimstra D and Brennan MF: Lymph node staging in gastric cancer: Is location more important than Number? An analysis of 1,038 patients. Ann Surg 232: 362-371, 2000.

23. Enzinger PC, Benedetti JK, Meyerhardt JA, McCoy S, Hundahl SA, Macdonald JS and Fuchs CS: Impact of hospital volume on recurrence and survival after surgery for gastric cancer. Ann Surg 245: 426-434, 2007.

24. Degiuli M, Sasako M and Ponti A; Italian Gastric Cancer Study Group: Morbidity and mortality in the Italian Gastric Cancer Study Group randomized clinical trial of D1 versus D2 resection for gastric cancer. Br J Surg 97: 643-649, 2010.

25. Degiuli M, Sasako M, Ponti A, Vendrame A, Tomatis M, Mazza C, Borasi A, Capussotti L, Fronda G and Morino M; Italian Gastric Cancer Study Group: Randomized clinical trial comparing survival after D1 or D2 gastrectomy for gastric cancer. Br J Surg 101: 23-31, 2014.

This work is licensed under a Creative Commons Attribution-NonCommercial-NoDerivatives 4.0 International (CC BY-NC-ND 4.0) License. 